\title{
From product dispensing to patient care: The role of the pharmacist in providing pharmaceutical care as part of an integrated disease management approach
}

\author{
Laura T. Pizzi \\ Thomas Jefferson University \\ Jean M. Menz \\ Novartis Pharmaceuticals \\ Geneen R. Graber \\ Novartis Pharmaceuticals \\ Dong-Churl Suh \\ Ruligershthpivefsitelditional works at: https://jdc.jefferson.edu/healthpolicyfaculty \\ Part of the Health Services Research Commons \\ Let us know how access to this document benefits you
}

\section{Recommended Citation}

Pizzi, Laura T.; Menz, Jean M.; Graber, Geneen R.; and Suh, Dong-Churl, "From product dispensing to patient care: The role of the pharmacist in providing pharmaceutical care as part of an integrated disease management approach" (2001). College of Population Health Faculty Papers. Paper 16.

https://jdc.jefferson.edu/healthpolicyfaculty/16

This Article is brought to you for free and open access by the Jefferson Digital Commons. The Jefferson Digital Commons is a service of Thomas Jefferson University's Center for Teaching and Learning (CTL). The Commons is a showcase for Jefferson books and journals, peer-reviewed scholarly publications, unique historical collections from the University archives, and teaching tools. The Jefferson Digital Commons allows researchers and interested readers anywhere in the world to learn about and keep up to date with Jefferson scholarship. This article has been accepted for inclusion in College of Population Health Faculty Papers by an authorized administrator of the Jefferson Digital Commons. For more information, please contact: JeffersonDigitalCommons@jefferson.edu. 


\title{
From Product Dispensing to Patient Care: The Role of the Pharmacist in Providing Pharmaceutical Care as Part of an Integrated Disease Management Approach
}

\author{
LAURA T. PIZZI, Pharm.D., ${ }^{1}$ JEAN M. MENZ, Pharm.D., ${ }^{2}$ GENEEN R. GRABER, Pharm.D., ${ }^{3}$ \\ and DONG-CHURL SUH, M.B.A., Ph.D. ${ }^{4}$
}

\begin{abstract}
During the past decade, the profession of pharmacy has changed dramatically. The Doctor of Pharmacy degree has replaced the Bachelor of Science degree as the first professional degree offered at most accredited U.S. pharmacy schools. Advanced clinical training is now a mainstay of pharmacy training, and this has enabled pharmacists to contribute to disease management efforts. In addition, technological improvements in prescription processing have afforded pharmacists more time to participate in disease management activities. This paper describes how the role of the pharmacist has changed and reviews the results of programs involving pharmacists as disease management providers in the areas of asthma, hypertension, diabetes, and hyperlipidemia. Pharmacists' contributions in various practice settings are also discussed.
\end{abstract}

\section{INTRODUCTION}

$\mathbf{T}$ HE PROFESSION OF PHARMACY is continuing to undergo a dramatic shift in focus from product dispensing to patient care. As technology advances to assume the task of dispensing, pharmacists are given the opportunity to concentrate on providing cognitive services for patients. With more advanced training, pharmacists have become a more integral part of the health care delivery team. The challenge is then for pharmacists to demonstrate their value in these alternative roles. As a result of this change, the Doctor of Pharmacy (Pharm.D.) degree is now the first professional degree attainable at all U.S. pharmacy schools but one. ${ }^{1}$ The Pharm.D. degree requires advanced clinical training through course work as well as experiential rotations.

Over the past few years, the disease management movement has driven health care toward a more outcomes driven approach to care. Disease management (DM) has been defined as a "systematic management tool applied to specific diseases with an emphasis on prevention and 'Best Practices' to provide highquality care at a reasonable cost with an ongoing process of monitoring and continuous improvement." 2

The growth of DM paralleled the growth of managed care delivery systems. The types of organizations that currently offer DM services

\footnotetext{
${ }^{1}$ Office of Health Policy and Clinical Outcomes, Thomas Jefferson University, Philadelphia, Pennsylvania.

${ }^{2}$ Neuroscience Scientific Operations, Novartis Pharmaceuticals, East Hanover, New Jersey.

${ }^{3}$ Cardiovascular Marketing, Novartis Pharmaceuticals, East Hanover, New Jersey.

${ }^{4}$ College of Pharmacy, Rutgers University, Piscataway, New Jersey.
} 


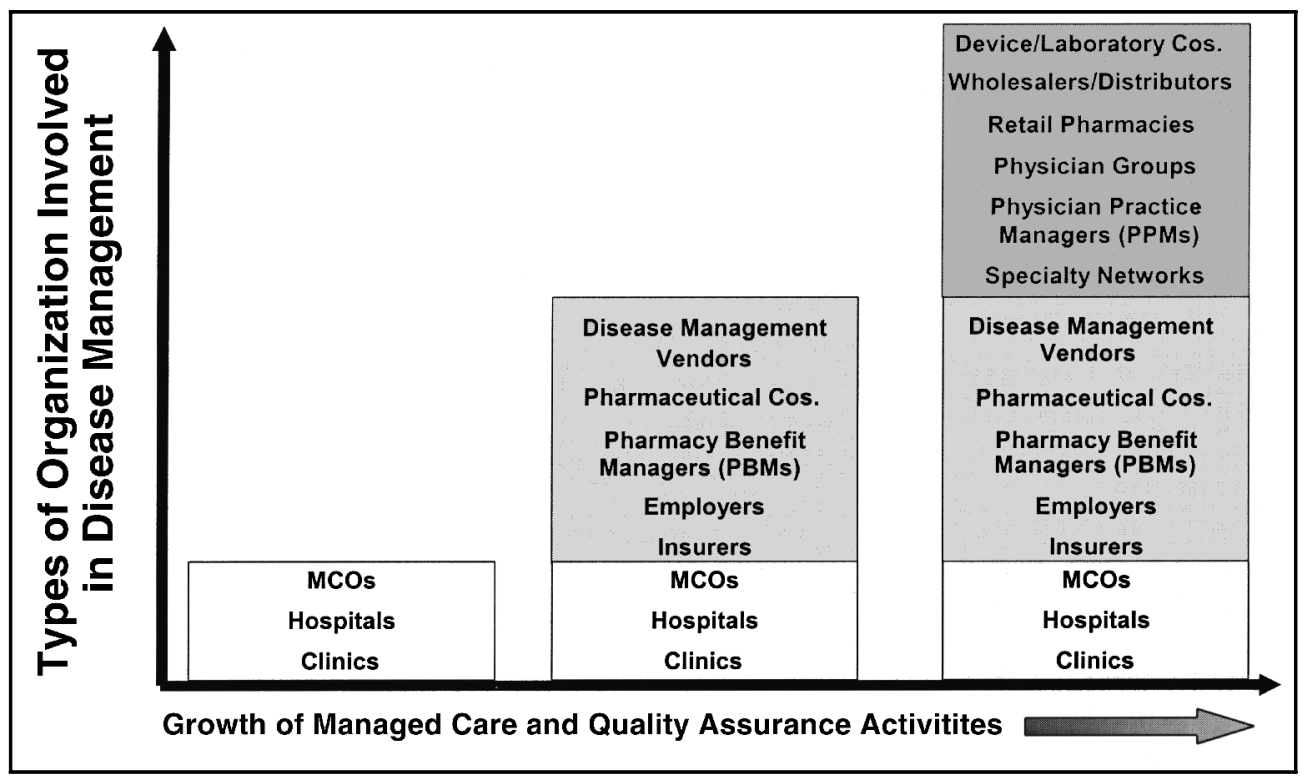

FIG. 1. Influence of the growth of managed care on the types of organizations participating in disease management.

now encompass virtually every stakeholder in the provision of healthcare. Although managing disease has always been a part of medical care, structured DM programs did not take hold until the early 1990s. Managed care organizations (MCOs), hospitals, and clinics are considered to be the originators of this movement and were later joined by pharmaceutical companies, pharmacy benefit managers (PBMs), large employers, and DM companies (Fig. 1). More recently, the healthcare industry has witnessed a surge of interest in DM among other organizations, such as device and laboratory companies, medical product wholesalers and distributors, physician groups, physician service organizations (PSOs), specialty (carveout) providers, and community pharmacies.

Pharmacists have been involved in the development and implementation of many DM programs in existence today. Some have contributed to the development and implementation of DM initiatives in settings that are not directly involved in patient care (PBMs, pharmaceutical companies), whereas others have participated in both the development and implementation in settings that do involve direct interaction with patients (MCOs, long-term care facilities, hospitals, home healthcare providers, integrated delivery systems, and community pharmacies).

\section{THE EXPANSION OF PHARMACIST- PRACTICED DISEASE MANAGEMENT}

The origin of pharmacist involvement in DM can be traced back to the inpatient setting. In an effort to demonstrate their value, clinical pharmacists began recording and tracking pharmacy interventions. During this early phase, pharmacist intervention was considered reactive, rather than proactive. That is, the bulk of interventions focused on correcting existing problems with drug therapy, such as eliminating drug interactions, as opposed to establishing systems to prevent problems.

Prior to the widespread use of the term "disease management," the concept of pharmaceutical care was introduced. ${ }^{3}$ Pharmaceutical care focuses on enhancing care for individual patients. Pharmaceutical care was defined as "the responsible provision of drug therapy for the purpose of achieving definite outcomes that improve a patient's quality of life." 3 In practicing pharmaceutical care, a pharmacist is expected to assume greater responsibility for patients' medication-related outcomes. ${ }^{4}$

The extent to which pharmacists practice pharmaceutical care is highly variable. For example, a 1996 study of Virginia pharmacists ${ }^{5}$ found that community pharmacists who prac- 
ticed pharmacy in independently owned pharmacies in rural Virginia and had a good rapport with patients and local physicians were more likely to deliver pharmaceutical care. In addition, prescription volume of greater than 150 prescriptions per day appeared to limit a pharmacist's ability to engage in pharmaceutical care. Although there may be important geographical differences, the findings from this study suggest that some higher volume retail chains were less likely to provide pharmaceutical care. However, technological advancements that have expedited the script processing may limit the current applicability of this finding.

The true impact of pharmaceutical care activities is still largely unknown. A review of published pharmaceutical care research ${ }^{6}$ concluded that few studies had evaluated the impact of pharmaceutical care in defined populations. Deficiencies among the published literature include the need for quality research design and a clear description of the pharmaceutical care process so that the impact could be properly evaluated. The growth of DM activites represents a shift in focus that may assist pharmacists in addressing some of the deficiencies noted in the pharmaceutical care literature. While pharmaceutical care stresses the optimization of outcomes in single patients, DM attempts to improve outcomes in the overall population by structured interventions aimed at patients with specific diseases. The framework provided by DM programs may enable more pharmacists to participate and effectively improve outcomes through education, patient targeting, and structured intervention. The application of DM techniques may serve to increase the efficiency and impact of pharmacist intervention in targeted disease states.

Studies suggest that the potential impact of pharmacist intervention may be significant. In a well-publicized modeling study, Johnson and Bootman ${ }^{7}$ calculated the annual cost of drugrelated morbidity and mortality at $\$ 76.6$ billion. In a follow-up study, Johnson and Bootman ${ }^{8}$ estimated that pharmacist intervention and pharmaceutical care could reduce the annual expense of drug misadventure by $\$ 45.6$ billion, or $59.6 \%$ of the total expenditure. This reduc- tion in costs is despite the fact that the model assumed pharmacists would be paid an additional \$10 for every patient encounter. In fact, the model was insensitive to pharmacists' fees, with the overall cost savings only decreasing to $\$ 44.7$ billion if pharmacists were paid $\$ 40$ per patient encounter.

\section{LEARNING FROM EXPERIENCE}

\section{The pharmacist's role in different practice settings}

Ambulatory care pharmacists as primary care providers. With increasing healthcare costs, increases in the number of available drugs and time pressures facing physicians, pharmacists emerged as a resource for managing diseases that are highly dependent on pharmacotherapy. The U.S. Indian Health Service (IHS) is considered to be a forerunner in this movement, by initiating pharmacist primary care visits for minor illnesses in the 1960s. ${ }^{9}$ Today, the IHS employs more than 500 pharmacists, and offers a Clinical Pharmacy Training Program (CPTP) that builds pharmacists' skills in the areas of medical history taking, laboratory test interpretation, differential diagnosis, patient consultation, record review, and conflict resolution. ${ }^{9}$ In addition, CPTP educates pharmacists on the pathophysiology and pharmacotherapy of the 10 most prevalent diseases within the IHS patient population. ${ }^{9}$ Within ambulatory care settings outside of the IHS, pharmacist-managed clinics have emerged in the areas of certain high-cost, chronic conditions (e.g., asthma, diabetes, hypertension, HIV , cardiovascular disease).

As the fields of DM and outcomes research became more defined, health services researchers began to study the impact of utilizing the pharmacist in this alternative role. In 1992, Kaiser Permanente and the University of Southern California began a study measuring the impact of three alternative models of pharmacist consultation on the use and cost of health care services: (1) consultation about new or changed prescriptions as mandated by state law, (2) consultation focused on selected highrisk ambulatory patients, and (3) a control model that maintained the standard of pharmacy practice prior to the November 1992 Cal- 
ifornia regulations (mandating pharmacist consultation). ${ }^{10}$ Data was collected on health status, satisfaction, and healthcare resource utilization. They concluded that counseling patients on their medications might be unlikely to reduce medication costs or the cost of office visits, but may reduce the likelihood of hospital admissions and the overall costs of healthcare services. ${ }^{11}$

In 1995, at Cedars-Sinai Health System in California, the health services research group developed a pharmacist-physician comanagement approach to providing healthcare in one of their medical groups. This approach provided pharmacists the opportunity to not only counsel patients on their disease, medications, and overall care plan, but also began developing a comanagement approach to delivering care with the physicians. The pharmacists presented the patient assessment to the physician and made recommendations for therapeutic adjustments based on evidence-based guidelines.

The researchers developed a randomized comparative DM trial to measure the impact of this approach for hypertension patient management, which compared a pharmacistphysician comanagement approach to delivering care with a physician alert approach (e.g., notifying a physician that a patient's blood pressure is out of control). Overall, the pharmacist-physician comanagement approach improved clinical outcomes (sustained blood pressure reduction) and economic outcomes (decreased per member per month costs) beyond that of the physician alert group. ${ }^{12}$ These results prompted Cedars-Sinai to offer this service to all hypertension patients, as well as nine additional disease states.

Industry pharmacists as disease management and outcomes research specialists. A growing area of interest for pharmacists has been pursuing the disciplines of DM and outcomes research within the pharmaceutical industry. Due to the increasing need for economic justification of pharmaceutical products, the pharmaceutical industry has developed extensive in house expertise in the areas of DM, outcomes research, health economics, and pharmacoeconomics. ${ }^{13}$ The pharmaceutical industry uses this exper- tise to determine the value of medical interventions.

Evidence of pharmacists' interest in industry opportunities is seen in the growth of advanced pharmacoeconomics and outcomes research training opportunities. Many pharmaceutical companies have established 1-2-year fellowship programs in which fellows have the opportunity to develop expertise in these disciplines by working alongside key researchers in these fields. These types of programs offer healthcare professionals the opportunity to gain insight into these fields from both the provider and industry perspective.

Community pharmacists as specialists in pharmaceutical care. The pharmaceutical care movement has also expanded into the community pharmacy setting. Since community pharmacists are centrally located and easily accessible, they are well positioned for this new role. Additionally, with automated dispensing and prescription margins decreasing, retail pharmacists are looking for alternative roles and new sources of revenue. Some large retail chains remodeled stores in preparation of this new movement, whereas others developed independent patient counseling centers where no dispensing actually takes place.

Retail chains are facilitating change from a clerk-customer relationship to healthcare provider-patient relationship by encouraging pharmacists to provide pharmaceutical care. However, the key to gaining acceptance and sustaining this new role is to demonstrate the pharmacist's value through collecting outcomes in terms that healthcare decision makers understand.

There are studies currently underway to implement these newer models of care. Some of the large retail chains have been very proactive in leading this movement. For example, Walgreens now offers four Care Management Programs in the areas of asthma, H. pylori, diabetes, and coronary artery disease (CAD). ${ }^{14} \mathrm{In}$ addition, CVS has established Health Connections centers in certain stores to deliver health information and management programs.

Another example is Eckerd, which has recently begun testing a few different models of community pharmacists implementing phar- 
maceutical care. In 1997, Eckerd began remodeling two of their stores in Atlanta, Georgia. In hopes of freeing up pharmacist time to spend with their patients, they reoriented the pharmacies with technological enhancements to automate about $50 \%$ of the pharmacy's dispensing. To complement these enhancements, patient consultation rooms were added specifically for pharmacist-patient medication counseling. This model would essentially allow for pharmacists within local stores to differentiate themselves-some as dispensing pharmacists and others as pharmaceutical care pharmacists. ${ }^{15}$ Additionally, in 1998, Eckerd opened the Eckerd Patient Care Center in Largo, Florida. This model is exclusively dedicated to patient counseling; no dispensing takes place on the premises. At this site, patients make appointments to meet with the pharmacists for education and review of their pharmaceutical care plans. Eckerd used these new models of care as a laboratory to collect outcomes data and validate whether they are, in fact, improving patient care. ${ }^{16}$

\section{Pharmacists' involvement in specific disease management efforts}

Typically, DM programs are developed for high-cost, chronic disease states. In the next few paragraphs, examples of pharmacist involvement in the disease states of asthma, hypertension, and diabetes will be reviewed.

Asthma. Asthma is a prevalent disorder affecting an estimated one in 25 million Americans, and over $\$ 6$ billion is spent annually to treat this disease. ${ }^{18}$ However, it is estimated that $40 \%$ of these costs are potentially avoided through better asthma management. ${ }^{17}$ Pharmacists dispense more than 7 million prescriptions annually to treat asthma. These frequent patient encounters place pharmacists in a unique position to improve the outcomes of asthma patients. The National Asthma and Education Program has recognized the potential of pharmacist intervention and has created a guide that describes the role of the pharmacist in asthma care. ${ }^{18}$ Pharmacist responsibilities delineated in this guide are described in Table 1. These guidelines provide an excellent frame-
Table 1. National Asthma Education Program Guidelines for Pharmacist Responsibilities in Asthma Disease Management

1. Educate patients about the role of each medication.

2. Instruct patients about the proper techniques for inhaling medications.

3. Monitor medication use and refill intervals to help identify patients with poorly controlled asthma.

4. Encourage patients purchasing nonprescription asthma inhalers or tablets to seek medical care.

5. Help patients use peak-flow meters appropriately.

6. Help patients discharged from the hospital after an asthma exacerbation to understand their asthma management plan.

Data from National Asthma Education and Prevention Program. ${ }^{18}$

work for defining the pharmacist's role in asthma DM.

An asthma DM program may assist pharmacists in structuring their efforts in managing asthma. Hunter and Bryant ${ }^{19}$ developed an educational intervention targeted at pediatric asthma patients and their parents. When surveyed prior to the intervention, only $14 \%$ of participants indicated that they were counseled by a pharmacist about the safe and effective use of asthma medications. More than half $(58 \%)$ felt they needed more information to effectively manage asthma, and $79 \%$ felt that, if they received more information, their child's illness would be better managed or controlled. All participants participated in the educational intervention that consisted of a 45minute presentation, a demonstration of drug delivery devices, and a question/answer/discussion session for participants to ask questions and share their experiences on handling difficult situations. After the intervention, $100 \%$ of participants replied that they had enough information to safely and effectively use asthma medications.

While it is encouraging to observe educational efforts by pharmacists reflected in improved survey ratings by patients, does this enhanced understanding lead to improved patient outcomes? A study of a pharmacistmanaged asthma program evaluated the impact of attending a special asthma clinic on pa- 
tients with frequent asthma exacerbations leading to emergency room (ER) utilization. ${ }^{20} \mathrm{Sub}$ jects were eligible for the study if they were seen in the ER a minimum of three times in a 12-month period. Twenty-five patients were enrolled and attended the asthma clinic. Frequency of asthma clinic visits were determined by the severity of the patients' illness and the patients' perceived understanding of the control of their illness. Other aspects of the program included regular telephone contact between patient and pharmacist and an opendoor clinic policy. Results of the program were encouraging. The 25 patients enrolled in the study visited the ER 92 times in the 6 months prior to study enrollment (47 times in the same 6 months of the year prior to the study). During the study period, there were only six ER visits for asthma exacerbations. Despite the cost of operating the clinic, the program resulted in significant cost savings. The program saved from $\$ 30,683$ (based on baseline ER utilization of 47 visits) to $\$ 68,393$ (based on 92 baseline visits).

Hypertension. Unlike asthma, which can be characterized by frequent exacerbations, hypertension is a largely asymptomatic disease. As with other asymptomatic diseases, patients are often noncompliant with therapy. This presents a challenge for healthcare practitioners since chronic uncontrolled hypertension can lead to sequelae such as stroke and heart attacks. However, the literature offers many encouraging examples of successful hypertension management programs. A controlled, randomized study was conducted in a retail pharmacy chain store. ${ }^{21}$ Patients were recruited if they were receiving antihypertensive medication or had a blood pressure greater than 140/90 mm $\mathrm{Hg}$. Twenty-seven patients were enrolled as intervention patients and 26 as control patients. Intervention patients participated in four scheduled monthly visits during which they received drug therapy monitoring (heart rate, blood pressure, medication history, compliance monitoring, drug interactions screening, and adverse drug effects screening) and patient education. Control patients received traditional pharmacy services, which were defined as screening for prescribing errors, prescription filling, limited patient education (i.e., drug regimen, potential side effects), and monitoring patient-volunteered adverse drug reactions. At the end of the 4-month study, results showed that blood pressure control was significantly improved in the study group. Medication compliance rates also improved in the study group, as well as the quality-of-life (Health Status Questionnaire 2.0) scale of energy and fatigue.

Pharmacists are often needed to act as physician extenders in rural areas. A pilot study evaluated the effectiveness of pharmacists in a rural hypertension clinic. ${ }^{22}$ Prior to the study, the pharmacists participated in an intensive skill development program. Fifty-one patients with controlled or uncontrolled hypertension were randomized to either the pharmacist intervention arm or the control arm of the study. Intervention patients were scheduled to see the pharmacist every 3-5 weeks. Blood pressure and pulse were measured, and patients were questioned regarding compliance, adverse drug reactions, and understanding of present drug regimens and lifestyle modifications. Standardized patient education pamphlets were distributed. The impact of the pharmacist intervention was positive. Blood pressure was reduced in the study group, a blinded peer review panel deemed the appropriateness of the blood pressure regimen to be significantly improved, and the quality-of-life domains of physical functioning, physical role limitations, and bodily pain significantly improved. No significant changes occurred in the control group. Additionally, patient satisfaction scores were significantly higher in the study group.

Although improved outcomes such as reduced blood pressure and improved quality of life are desirable, economic outcomes must also be examined given the increasing pressure on financial resources within the health care system. Interim results of an evaluation of a DM program at Cedars-Sinai Health System demonstrated that utilizing the pharmacist-physician comanagement approach to management of hypertension may lead not only to improved quality of care, but also to potential cost savings. ${ }^{23}$ Patients with uncontrolled hypertension were randomized to an alert group, where the primary care physician received a letter informing him or her of the patient's uncon- 
trolled status, or an intervention group. Intervention patients were enrolled in a pharmacist clinic where a pharmacist comanaged the patients with the physicians until blood pressure goals were achieved. The interim results suggest that both patients in the alert and intervention groups had decreases in blood pressure. However, blood pressure drops were more substantial in the intervention group, decreasing from a baseline $157.7 \mathrm{~mm} \mathrm{Hg}$ systolic pressure to $148.9 \mathrm{~mm} \mathrm{Hg}$ and $139.6 \mathrm{~mm} \mathrm{Hg}$, at 6 months and 1 year, respectively, when compared with the alert group. The alert group decreasing from a baseline of $153.4 \mathrm{~mm} \mathrm{Hg}$ to $151.7 \mathrm{~mm} \mathrm{Hg}$ and $144.6 \mathrm{~mm} \mathrm{Hg}$, at 6 months and 1 year, respectively. At 6 months, total cost of treatment per member per month (PMPM) increasing, mainly because of an increased number of patient visits. At 1 year, however, the costs of laboratory tests, office visits, and medications decreased, resulting in average savings of \$6.40 PMPM.

Diabetes. In addition to asthma and hypertension, pharmacists have also demonstrated a positive impact in the management of diabetes. Two studies ${ }^{24,25}$ evaluated the impact of pharmacist management on outcomes in diabetes. Jaber and colleagues examined the impact of pharmacist-provided diabetes education, medication counseling, and evaluation and adjustment of the medication regimen in 39 non-insulin-dependent diabetics (NIDDM) attending a university-affiliated outpatient clinic. After 4 months, the patients who were managed by a pharmacist were found to have significant improvements in hemoglobin A1c and fasting plasma glucose. No changes in glycemic control were found in the control group, and no changes were observed in either group for blood pressure control, lipid profile, renal function, weight, or quality of life. The second study compared a control group of diabetic patients receiving standard pharmacist education to a treatment group receiving additional small group or individual supplementary education for a 2-month period. As in the first study, the intensive education improved outcomes. Patients in the treatment group had significantly lower average weekly blood glucose levels and a decreased incidence of hyperglycemic events.
Patients in the treatment group demonstrated a significant increase in their understanding of diabetes medications and blood glucose monitoring and a positive difference in their perception and attitude towards diabetes and communication with the pharmacist. This positive attitude toward communication with the pharmacist could have a beneficial impact over the course of a chronic disease.

Hyperlipidemia. According to the American Heart Association approximately 99.5 million Americans have blood cholesterol levels of 200 $\mathrm{mg} / \mathrm{d}$ or higher. ${ }^{26}$ Lipid management is known to reduce cardiovascular events, resulting in the recent update of treatment guidelines by the National Cholesterol Education Program Expert Panel (NCEP). ${ }^{27}$ As a result of the new guidelines, it is estimated that the number of Americans who are candidates for cholesterollowering medications will triple. ${ }^{28}$ This projection points to an increased need for pharmacist involvement in lipid management.

Several studies have evaluated the effectiveness of pharmacist-administered lipid management programs. Ellis and colleagues examined the effectiveness of pharmacist intervention in the management of dyslipidemia among Veterans Administration patients. ${ }^{29}$ They conducted a prospective, randomized, controlled trial involving 437 patients at nine VA medical centers. Patients were randomized to either the intervention group (were scheduled for follow-up with an ambulatory care pharmacist) or control group (received usual medical care). Outcome goals were established using the published guidelines, and costs were calculated using the VA Medical Center's Decision Support System. Results demonstrated that the intervention group achieved a statistically significant reduction in both total cholesterol and low-density lipoprotein, compared to the control group.

A smaller study by Faulkner and colleagues assessed the impact of pharmacist counseling on compliance and effectiveness of lipid-lowering drugs. ${ }^{30}$ This study also employed a randomized, controlled design but was aimed at determining the effectiveness of pharmacist telephone follow-up. The sample included 30 patients (15 intervention, 15 control) who had 
recently undergone coronary artery revascularization at a university-affiliated hospital in Omaha, Nebraska. Patients in the intervention group were telephoned by a pharmacist once a week for 12 weeks to emphasize the importance of lipid-lowering therapy, assess refills, and identify potential issues related to compliance (drug cost, side effects, overall well-being). Results showed that the intervention provided no short-term benefit during the first 12 weeks of therapy, but compliance and lipidlowering results were better in the intervention group in the long-term (measured 2 years after the start of therapy). Although these results provided mixed evidence surrounding the effectiveness of the intervention, the study suggests that pharmacist telephone follow-up may be useful, particularly when in-person clinic visits are impractical or impossible (e.g., in rural areas or in medical centers that do not have space or funding for a pharmacist-run clinic).

Carson investigated the effectiveness of pharmacist consultation notes added to the charts of hyperlipidemic patients. Patients were low-income adults receiving treatment at a medicine clinic that is affiliated with a health center in a depressed area of Albany, New York. ${ }^{31}$ NCEP II guidelines served as the basis for identifying risk factors and recommended treatment regimens. An observational, singlegroup design was employed in which a cohort of primary and secondary prevention patients were followed for use of risk-reducing medications. Results demonstrated an increase in the number of patients prescribed lipid-lowering therapy during the study period, compared to baseline. ${ }^{32}$ Although clinical outcome measures such as cholesterol and/or lipoprotein levels were not discussed, findings suggest that pharmacist chart notes may help to increase physician compliance with guidelines for prescribing lipid-lowering therapies.

An earlier study by Bogden and colleagues measured the impact of a pharmacist-physician team on the ability to reach lipid-lowering goals. ${ }^{33}$ The setting was a university-affiliated medicine clinic in Honolulu, Hawaii. A singleblind, randomized, controlled design was used to compare those receiving the intervention to a control group receiving usual care. The in- tervention consisted of routine pharmacistpatient consultations, including recommendations on dosage, appropriate drug treatments, and monitoring. NCEP guidelines were used to guide the appropriate initiation of therapy, as well as to set lipid-lowering goals. Results revealed that twice as many intervention patients reached their lipid-lowering goals compared to patients in the usual care group.

\section{A LEGISLATIVE MILESTONE FOR PHARMACISTS}

In July 1998, a legislative milestone was reached for pharmacists. The approval of a Medicaid waiver granted reimbursement for pharmacists providing DM services in the state of Mississippi. Under this legislation, pharmacists with appropriate training can be reimbursed for providing cognitive services for patients with diabetes, asthma, lipid disorders, and anticoagulation under patient-specific treatment protocols approved by a physician. In order to qualify as a provider under the waiver, pharmacists must be credentialed in each of the therapeutic areas included. The requirements for reimbursement under this law are provided in Table 2.

In response to this legislation and the need for pharmacists across the country to receive advanced training to qualify as DM providers for independently run programs, the National

\section{Table 2. Requirements for Pharmacist REIMBURSEMENT UNDER THE Mississippi Medicaid Waiver}

1. The pharmacist must complete a credentialing program that is approved by the state Board of Pharmacy.

2. The pharmacist must obtain a written referral from the patient's physician.

3. The pharmacy at which the credentialed pharmacist practices must have a private counseling area.

4. A record of services provided to the patient must be maintained in the pharmacy.

5. The pharmacist must obtain a provider number from the state Medicaid department.

Data from National Association of Boards of Pharmacy. ${ }^{34}$ 
Association of Boards of Pharmacy (NABP), American Pharmaceutical Association (APhA), National Association of Chain Drug Stores (NACDS), and the National Community Pharmacists' Association (NCPA) collaborated to form the National Institute for Standards in Pharmocist Credentialing (NISPC). NISPC currently offers pharmacists certifications in the areas of asthma, diabetes, and anti-coagulation. ${ }^{35}$

\section{THE FUTURE: GROWTH OF DISEASE MANAGEMENT WITHIN COMMUNITY PHARMACIES}

Although the advanced training that is currently being delivered will assist all pharmacists in delivering pharmaceutical care, some feel that the greatest potential may very well lie within the "corner drugstore." Several factors render this setting desirable for the provision of DM services. These factors are related to the dynamics of community pharmacy practice: patient access, consistency between sites, data collection mechanisms, and rising drug costs.

\section{Dynamics of pharmacy practice}

Within the community, pharmacists practice at the interface of care and therefore have the ability to interact with consumers and patients. Public opinion polls reveal that pharmacists are consistently ranked among the most trusted professionals. ${ }^{36}$ Figure 2 illustrates the drug prescribing process in relation to the organizations that currently offer DM. Because pharmacists, similarly to physicians, have the ability to directly deliver DM services, they have the ability to serve as conduits for implementing programs developed by health insurance providers, pharmacy benefit managers, pharmaceutical companies, wholesalers and distributors, and employers. It is important to note that this figure is restricted in focus to the prescribing process and does not depict the roles that other allied health professionals play in delivering DM.

\section{Patient access}

In addition to existing at the interface, community pharmacies offer virtually open access to patients. There are presently more than 50,000 pharmacies in the United States (Table 3 ) and more than 128,000 pharmacists practicing at these sites. ${ }^{37}$ Most stores are open at least 6 days per week, and many now offer 24-hour prescription services. Furthermore, there are no appointments or insurance preapprovals required in order to receive one-on-one profes-

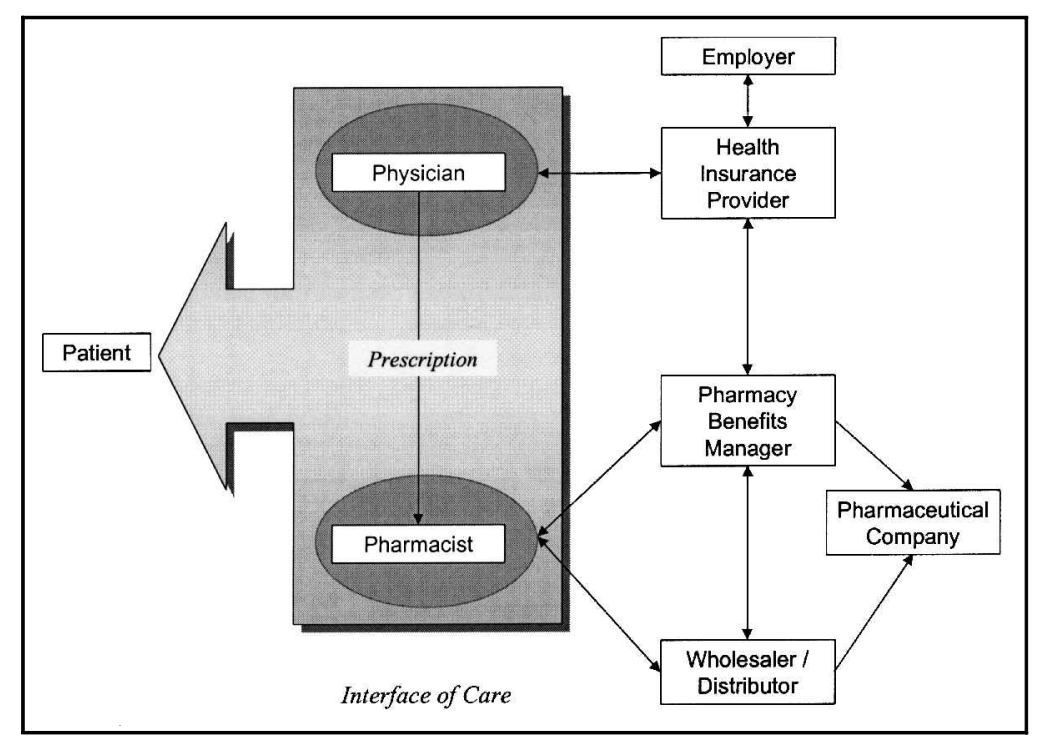

FIG. 2. The prescribing process empowers pharmacists to deliver pharmaceutical disease management. Ovals illustrate the infrastructure in which pharmacists and physicians practice (e.g., group or clinic for physicians and corporate chain for pharmacists). 
Table 3. U.S. Pharmacy Demographics,

Excluding Mail Order Facilities, 1998

\begin{tabular}{lcc}
\hline Type of pharmacy & Number of stores & Prescription volume (1998) \\
\hline Traditional chain & 19,638 & 1.08 billion \\
Independents & 19,717 & 721 million \\
Food/drug stores & 6,838 & 310 million \\
Mass merchandisers & 4,931 & 284 million \\
Total & 51,124 & 2.4 billion \\
\hline
\end{tabular}

Data from National Association of Chain Drug Stores. ${ }^{37}$

sional consultations with the pharmacist. Finally, patients who are receiving chronic medications are likely to visit their pharmacy regularly in order to obtain refills, with the exception of certain conditions for which insurers may allow extended days' supply. Overall, the community pharmacy is a convenient location for health and DM program implementation.

\section{Consistency between sites}

Another attractive characteristic that is unique to chain pharmacies is an ability to administer a program at multiple stores. This is an important attribute for programs targeted at large or geographically dispersed patient populations because it provides the infrastructure required for implementation. Moreover, administering a single program over multiple sites allows for consistency that enhances the credibility of results.

There are also some practical benefits to implementing DM within a pharmacy chain. For example, administrative approval need only be sought from one party, data may be obtained from a single repository, and there is likely to be a process in place for communicating with the sites. In addition, the structural layout of the stores may be similar, which could be important if a patient counseling area is required for delivering the program.

\section{Data collection mechanisms}

In contrast to many other segments of healthcare, the data collection capability of community pharmacies is advanced. Because data capture and processing are functional require- ments of community pharmacies, most systems are prompt and reliable. An electronic record (consisting primarily of patient demographics and prescription history) is maintained for each patient. While these data are currently quite limited in scope, it is likely that advances in technology will allow for greater connectivity between the patient's pharmacy and medical encounters.

\section{Increasing drug costs}

In the face of the most dramatic increase in drug costs in history, one cannot discount the possibility that attention will be drawn to pharmacies as an intervention point to optimize utilization. In recent years prescription drug spending has risen about $15-20 \%$ per year ${ }^{38,39}$ and is expected to continue to increase. ${ }^{40}$ According to industry analysts, drugs accounted for $11-14 \%$ of total healthcare expenditures in 1998 , which represents a $7 \%$ increase from the early 1990s. ${ }^{39}$ Although the management of drug costs alone does not qualify as DM, it is likely that insurers and employers will attempt to manage drug costs as a part of broader initiatives.

\section{CONCLUSION}

The profession of pharmacy has undergone dramatic changes over the past decade. The DM movement, along with technological improvements in prescription processing, has allowed pharmacists to focus on patient care. Pharmacists in a variety of practice settings are participating in DM and are beginning to demonstrate their value in the management of several high-cost diseases, including asthma, hy- 
pertension, poststroke anticoagulation, and diabetes.

It has been estimated that traditional prescription processing utilizes only about $10 \%$ of the technologic potential computers have to offer pharmacists. ${ }^{41}$ As pharmacists become more involved in managing chronic diseases, expanding technology will enhance their efforts. Software applications to assist pharmacists in DM have been developed and will continue to be improved. Ultimately, pharmacy information systems will support the processes of drug dispensing, prescription processing, and the task of outcomes data collection, documentation, and monitoring. ${ }^{42}$

In addition, the advanced clinical training provided by pharmacy schools, major healthcare providers, and accrediting bodies will better equip pharmacists with the knowledge and skills required to contribute to DM. Although most pharmacists' DM contributions to date have been made in ambulatory care and industry settings, it is anticipated that DM will continue to grow within organizations concerned with health management. It is essential that outcomes data surrounding these activities be collected in order to continue to substantiate the value of pharmacists' contributions to patient care through DM.

\section{REFERENCES}

1. American Association of Colleges of Pharmacy. Academic pharmacist's vital statistics. March 2001. Available at: http://www.aacp.org.

2. John Deere Health Care, Inc., National Managed Health Care Congress Meeting, 1997.

3. Hepler CD, Strand LM. Opportunities and responsibilities in pharmaceutical care. Am J Hosp Pharm 1990;47:533-43.

4. American Society of Health-System Pharmacists. ASHP guidelines on a standardized method for pharmaceutical care. Am J Health Syst Pharm 1996;53: 1713-6.

5. Sisson EM, Israel MK. Extent of community-based delivery of pharmaceutical care in Virginia. Pharmacotherapy 1996;16:94-102.

6. Kennie NR, Schuster BG, Einarson TR. Critical analysis of the pharmaceutical care research literature. Ann Pharmacother 1998;32:17-26.

7. Johnson JA, Bootman JL. Drug-related morbidity and mortality: a cost-of-illness model. Arch Intern Med 1995;155:1949-56.
8. Johnson JA, Bootman JL. Drug-related morbidity and mortality and the economic impact of pharmaceutical care. Am J Health Syst Pharm 1997;54:554-8.

9. Paavola FG, Dermanoski KR, Pittman RE. Pharmaceutical services in the United States Public Health Service. Am J Health Syst Pharm 1997;54:766-72.

10. Nichol MD, Michael L. A critical analysis of the content and enforcement of mandatory consultation and patient profile laws. Ann Pharmacother 1992;26:114955.

11. McCombs JS, Liu G, Shi J, et al. The Kaiser Permanente/USC patient consultation study: change in use and cost of health care services. Am J Health Syst Pharm 1998;55:2485-99.

12. Deutsch SC, Denton M, Borenstein J. Clinical practice guidelines: a tool to help provide quality care. Geriatrics 1998;53:57-75.

13. Rinde $H$. Disease management in pharmaceutical companies. In: Couch JB, ed. The health care professional's guide to disease management: patient-centered care for the 21st century. Gaithersburg, MD: Aspen Publishers, 1998:223-254.

14. Walgreens company overview [on-line]. Available: www.walgreens.com/about/press/facts/fact2.jhtml.

15. Eckerd pharmacy revamps for future. The Atlanta Journal-Constitution 25 April 1998.

16. Novartis to conduct outcomes studies through Eckerd Patient Care Center. The Pink Sheet 30 November 1998.

17. Williams DM. Asthma management can save lives. Am Pharm 1995;NS35:3.

18. National Asthma Education and Prevention Program. The role of the pharmacist in improving asthma care (NIH publication no. 95-3280). Bethesda, MD: National Heart, Lung, and Blood Institute, 1995.

19. Hunter KA, Bryant BG. Pharmacist-provided education and counseling for managing pediatric asthma. Patient Educ Couns 1994;24:127-34.

20. Pauley TR, Magee MJ, Cury JD. Pharmacist-managed, physician-directed asthma management program reduces emergency department visits. Ann Pharmacother 1995;29:5-9.

21. Park JJ, Kelly P, Carter BL, Burgess PP. Comprehensive pharmaceutical care in the chain setting. J Am Pharm Assoc 1996;NS36:443-51.

22. Carter BL, Barnette DJ, Chrischilles E, Mazzotti GJ, Asali ZJ. Evaluation of hypertensive patients after care provided by community pharmacists in a rural setting. Pharmacotherapy 1997;17:11274-85.

23. Cedars-Sinai hypertension programs sees savings, lower PB. Rep Med Guidelines Outcomes Res 1997;19:1-5.

24. Jaber LA, Halapy H, Fernet M, Tummalapalli S, Diwarkaran H. Evaluation of a pharmaceutical care model on diabetes management. Ann Pharmacother 1996;30:238-43.

25. Van Veldhuizen-Scott MK, Widmer LB, Stacey SA, Popovich NG. Developing and implementing a pharmaceutical care model in an ambulatory care setting for patients with diabetes. Diabetes Educ 1995;21:117-23. 
26. American Heart Association. Cholesterol Statisitcs. Available at: www.americanheart.org.

27. Expert Panel on Detection, Evaluation, and Treatment of High Blood Cholesterol in Adults. Executive Summary of the Third Report of the National Cholesterol Education Program (NCEP) Expert Panel on Detection, Evaluation, and Treatment of High Blood Cholesterol in Adults (Adult Treatment Panel III). JAMA 2001;285(19):2486-97.

28. Kolata G. U.S. panel supports widespread use of cholesterol drugs. NY Times 16 May 2001.

29. Ellis SL, Carter BL, Malone DC, et al. Clinical and economic impact of ambulatory care clinical pharmacists in management of dyslipidemia in older adults: the IMPROVE study. Impact of Managed Pharmaceutical Care on Resource Utilization and Outcomes in Veterans Affairs Medical Centers. Pharmacotherapy 2000;20(12):1508-16.

30. Faulkner MA, Wadibia EC, Lucas BD, Hilleman DE. Impact of pharmacy counseling on compliance and effectiveness of combination lipid-lowering therapy in patients undergoing coronary artery revascularization: a randomized, controlled trial. Pharmacotherapy 2000;20:410-6.

31. Carson JJ. Pharmacist-coordinated program to improve use of pharmacotherapies for reducing risk of coronary artery disease in low-income adults. Am J Health Syst Pharm 1999;56:2319-24.

32. Tsuyuki RT, Johnson JA, Koon KT, et al. Study of cardiovascular risk intervention by pharmacists (SCRIP): a randomized trial design of the effect of a community pharmacist intervention program. Ann Pharmacother 1999;33:910-9.

33. Bogden PE, Koontz LM, Williamson P, Abbott RD. The physician and pharmacist team: an effective approach to cholesterol reduction. J Gen Intern Med 1997;12:158-64.

34. National Association of Boards of Pharmacy. An- swers Questions on DSM Exams/Credentialing. NABP Newsletter, September 1998. Available at: http://nabp.net.

35. National Institue for Standards in Pharmacist Credentilaing (NISPC) Organizational History. Available at: http://www.nispcnet.org/about_NISPC.html\# history

36. Honesty and Ethics Poll. Gallup Organization. November 27, 2000. Available at: www.gallup.com/ poll/releases/pr 001127iii.asp

37. National Association of Chain Drug Stores. Facts at a Glance 1998.

38. Patients facing higher costs for prescription drugs. New York Times 25 January 1999.

39. Winslow R. Co-payments rise for prescriptions as managed care plans rein in costs. Wall Street Journal 12 January 1999.

40. Anonymous. Multi-year, double-digit growth for Rx drug sales predicted. Med Marketing Media 1998; 33:22.

41. Felkey BG, Barker KN. Technology and automation in pharmaceutical care. J Am Pharm Assoc 1996;NS36: 309-14.

42. West DS, Szeinbach S. Information technology and pharmaceutical care. J Am Pharm Assoc 1997;NS37: 497-501.

Address reprint requests to: Laura T. Pizzi, Pharm.D. Project Director Office of Health Policy and Clinical Outcomes Thomas Jefferson University 1015 Walnut Street, Suite 115 Philadelphia, PA 19107

E-mail: laura.pizzi@mail.tju.edu 